\title{
O Uso de Ferramentas Digitais para Auxilio ao Programa de Planejamento Familiar: Uma Investigação
}

\author{
The Use of Digital Tools to Assist the Family Planning Program: A Preliminary \\ Investigation.
}

CAIO, Maria Paula; Mestranda; Universidade Federal de Pernambuco

caio.mariapaula@gmail.com

CASTILLO, Leonardo; Phd; Universidade Federal de Pernambuco

leonardo.a.gomez@gmail.com

DANTAS, Ney; Phd; Universidade Federal de Pernambuco

ney.dantas@gmail.com

\section{Resumo}

O presente artigo apresenta o resultado do processo de criação em artefatos digitais aplicado ao design social, com o objetivo de desenvolver uma ferramenta através dos conceitos trazidos por Geoff Mulgan (2007) e Manzini $(2004,2013)$ a respeito de Inovação Social e Design para Inovação Social. Com auxílio do toolkit, DIY, Development Impact \& You (2014) e entrevistas com assistentes sociais e pacientes do Programa de Planejamento Familiar do Sistema Único de Saúde (SUS) foi possível desenvolver um estudo preliminar para ideação de um aplicativo que auxilie o programa, com base nos conceitos estudados, capaz de fortalecer a interação entre os pacientes e os agentes de saúde envolvidos no processo.

Palavras Chave: Design para Inovação Social, Artefato Digital e Planejamento Familiar.

\begin{abstract}
This article presents the result of the creation process in digital artefacts applied to social design, with the objective of developing a tool through the concepts brought by Geoff Mulgan (2007) and Manzini $(2004,2013)$ about Social Innovation and Design for Social Innovation. With the aid of the toolkit, DIY, Development Impact \& You (2014) and interviews with social workers and patients of family planning program from the national health system (SUS) was possible to develop a preliminary study to create an app, that supports the program based on the studied concepts, capable of improve the interaction between the patients and the health professionals involved in the process.
\end{abstract}

Keywords: Design for Social Innovation, Information Appliance and Family Planning. 


\section{Introdução}

Estima-se que 222 milhões de meninas e mulheres que não querem engravidar, ou que querem atrasar sua próxima gravidez, não utilizam qualquer método contraceptivo. (ONU, 2014).

Assegurado pela Constituição Federal e, também, pela Lei $\mathrm{n}^{\circ} 9.263$, de 1996, o planejamento familiar é um conjunto de ações que auxiliam as pessoas que pretendem ter filhos, bem como as que preferem adiar o crescimento da família. Embora seja lei, a Pesquisa Nacional de Demografia e Saúde da Criança e da Mulher (PNDS), feita em 2006, financiada pelo Ministério da Saúde, revelou que $46 \%$ das gravidezes não são planejadas.

Segundo a ONU (2014), nos países de renda média e baixa, as complicações da gravidez e do parto estão entre as principais causas de morte em mulheres jovens com idade entre 15 e 19 anos. Natimortos e morte na primeira semana de vida é $50 \%$ maior entre os bebês nascidos de mães menores de 20 anos do que entre os bebês nascidos de mães com idade entre 20 e 29 anos.

As populações mais vulneráveis à falta de acesso a serviços de contracepção são jovens, pobres e que vivem em áreas rurais ou favelas urbanas. Esforços têm sido feitos para atender a essa necessidade desde a Cúpula de Planejamento Familiar, realizada em 2012, em Londres, na qual foi feita a promessa de que serviços de planejamento familiar alcançariam pelo menos 120 milhões de pessoas a mais até 2020. (ONU, 2014)

No Brasil, a Política Nacional de Planejamento Familiar foi criada em 2007. Ela inclui oferta de oito métodos contraceptivos gratuitos pelo Sistema Único de Saúde (SUS) e, também, a venda de anticoncepcionais a preços reduzidos na rede Farmácia Popular.

Logo, entende-se o Planejamento familiar como uma necessidade social. Com o intuito de fortalecer o programa, um estudo preliminar foi realizado à procura de um artefato digital (que compreendem qualquer produto com informatização embutida) capaz de melhorar a relação entre as pacientes e agentes de saúde, estruturado nos conceitos de design para inovação social.

O processo de criação desse artefato será aqui descrito e foi constituído por entrevistas realizadas na Maternidade Professor Bandeira Filho, com a chefe do Serviço Social e pacientes do programa de planejamento familiar, além da aplicação de ferramentas encontradas no toolkit DIY, Development Impact \& You (2014).

\section{Inovação Social}

Peter Drucker, teórico e consultor da área de administração, e Michael Young, empreendedor social e fundador da Open University são considerados os responsáveis pela disseminação do termo "Inovação Social" surgido nos anos 1960, embora só tenha ganhado espaço na última década (ROBERT, 2011).

Geoff Mulgan (2007) no livro "what it is, why it matters and how it can be accelerated" define inovação social como novas ideias que funcionam no cumprimento de metas sociais. Ou seja, atividades inovadoras e serviços motivados pelo objetivo de atender a uma necessidade social e que são predominantemente desenvolvidos e difundidos através de organizações cujos propósitos principais são sociais. Isto diferencia a inovação social de inovações comerciais que são geralmente motivadas pela maximização do lucro. $O$ interesse neste caso é, principalmente, com inovações que assumem a forma de programas replicáveis ou organizações. 
Manzini (2008) define inovação social como mudanças no modo como indivíduos ou comunidades se comportam para solucionar seus problemas ou gerar novas oportunidades. Algumas diretrizes são apontadas para avaliar precisamente a sua efetiva contribuição à sustentabilidade ambiental e social (Manzini, Jegou, 2003; Manzini, Meroni, 2007): 1. Capacidade inaudita de articular interesses individuais com interesses sociais e ambientais; 2 . Casos que em sua busca por soluções concretas, acabam por reforçar o tecido social, gerando e colocando em prática ideias novas e mais sustentáveis de bem-estar; 3 . Constituem ideias que dão grande valor à qualidade de nossos "bens comuns"; 4. Atitude respeitosa e atenta, à busca por um ritmo mais lento de vida; 5 . Ação colaborativa; 6 . Novas formas de comunidade e a novos conceitos de "localidade".

Através das diretrizes apresentadas é possível analisar e validar a efetividade dessas novas ideias que buscam atender a necessidades sociais existentes.

Phills, Deiglmeier e Miller (2008) acreditam que várias inovações sociais são bases para o surgimento de novos modelos de negócio que, com efetividade, podem servir as populações carentes, podendo ser lucrativos ou pelo menos economicamente sustentáveis, com estruturas de baixo custo e canais de entrega eficientes - frequentemente juntando visões de mercado e de não mercado. Essas inovações podem partir de lugares e pessoas não ligadas a empreendimentos sociais, de grandes organizações sem fins lucrativos e até mesmo de governos, desde que, mesmo que paralelamente a outros objetivos, estejam agregando algum valor social.

\section{Design para Inovação Social}

Criatividade pode ser definido como a capacidade de reorganizar elementos já existentes em novas e significativas combinações, de modo que podemos então definir comunidades criativas como: pessoas que, de forma colaborativa, inventam, aprimoram e gerenciam soluções inovadoras para novos modos de vida (MERONI, 2007).

Mesmo que essas comunidades não sejam totalmente planejáveis, através do design é possível fomentar seu nascimento e facilitar a sua existência, defende Manzini (2008). Designers podem dar suporte necessário para o escalonamento, replicabilidade, efetividade e longevidade dessas organizações colaborativas através de sistema de produtos, serviços e comunicação, trabalhando em conjunto com diferentes grupos de atores e interlocutores que já planejam e colocam em prática diariamente, mesmo sem possuir a expertise dos designers.

Para isso se faz necessário o desenvolvimento de novas habilidades. O designer precisa: promover a colaboração entre diferentes atores sociais (comunidades locais e firmas, instituições e centros de pesquisa); participar na construção de visões e cenários compartilhados; combinar produtos e serviços já existentes para suportar a específica comunidade criativa com a qual colaboram (MANZINI, 2008).

Sendo assim, podemos concluir que, segundos os autores citados acima, o design para inovação social busca auxiliar atividades inovadoras e serviços motivados pelo objetivo de atender a uma necessidade social.

\section{Procedimentos Metodológicos}

Sob a ótica do Design para inovação social, a equipe formada por três mestrandos em Design utilizou diversas ferramentas nas etapas de desenvolvimento de um artefato digital. A 
seguir serão descritas em ordem cronológica os métodos e resultados obtidos em cada fase da pesquisa.

\subsection{Observação direta intensiva despadronizada não dirigida}

A primeira etapa metodológica consistiu na entrevista com a chefe do serviço social da maternidade Professor Bandeira Filho, localizada no bairro de Afogados - Recife, Pernambuco.

O método utilizado foi a observação despadronizada não dirigida, na qual o entrevistado tem liberdade para desenvolver cada situação em qualquer direção que considere adequada. $A$ função do entrevistador é de incentivo, levando o informante a falar sobre determinado assunto, sem forçá-lo a responder (LAKATOS E MARCONI, 2007; ANDER-EGG, 1978). A entrevistada assinou o Termo de Consentimento Livre e esclarecido (TCLE) conforme anexos.

Através dessa entrevista foi possível entender, pela ótica do Serviço Social, como vem sendo aplicado o Programa de Planejamento Familiar do SUS e quais são suas principais carências e dificuldades.

\subsection{Problem Definition}

Problem Definition foi a segunda ferramenta utilizada no processo e foi extraída do DIY, Development Impact \& You (2014), conforme Figura 1.

Figura 1: Problem Definition

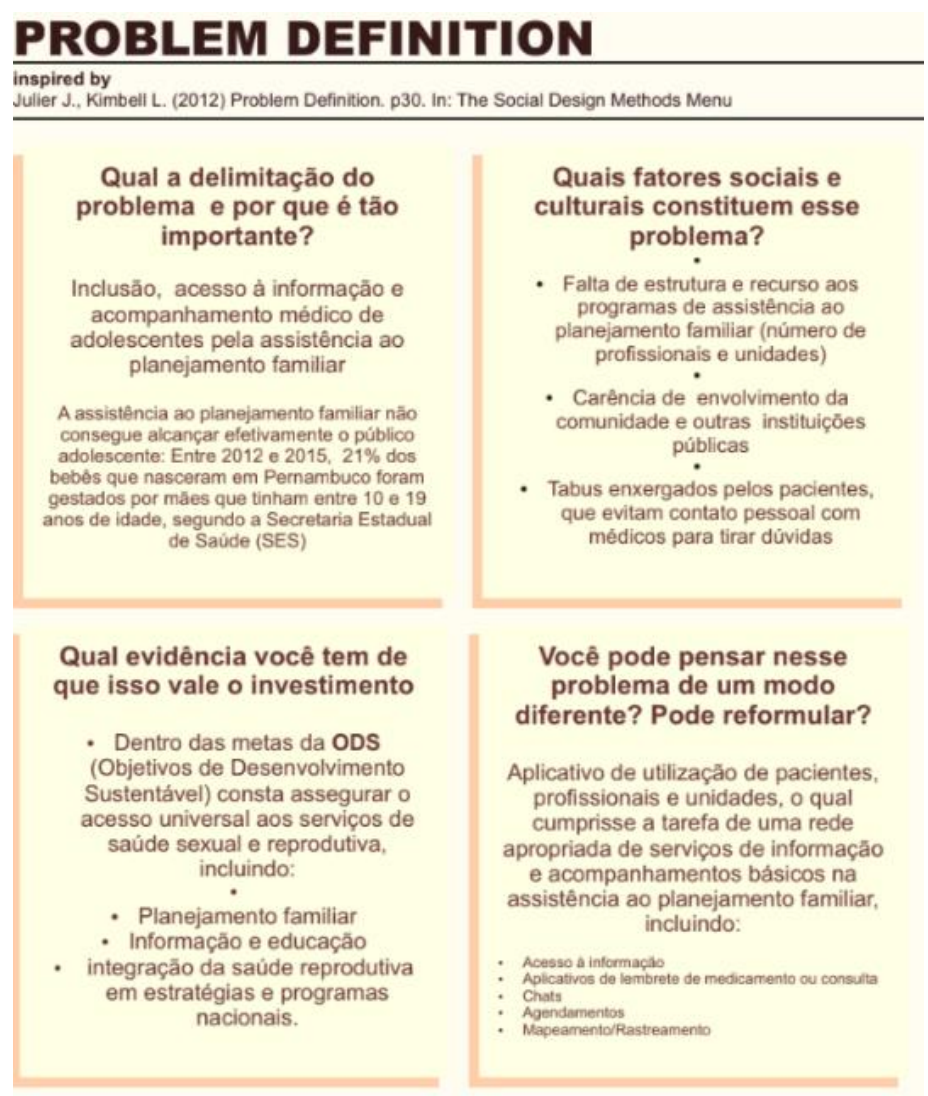

Fonte: Elaborado pelo autor, com base na pesquisa realizada 
Ela funciona tanto para destrinchar um problema - apresentar de forma que possa ser examinado de vários ângulos - como ajudar a definir o contexto e questões envolvidas. Essa ferramenta foi feita para estruturar e analisar um problema particular de forma que o tempo seja aproveitado. Apresenta um pequeno conjunto de critérios-chave para o qual uma questão pode ser articulada e avaliada. Também fornece uma maneira padronizada de comparar diversos problemas que poderiam parecer muito diferentes superficialmente.

Com o desenvolvimento dessa ferramenta foi definido e analisado a necessidade social que seria auxiliada através do desenvolvimento de um novo artefato digital: Planejamento Familiar.

\subsection{Experience Tour}

A partir da pesquisa Bibliográfica e da entrevista com a assistente social foi possível aplicar o Experience Tour (Figura 2).

Figura 2: Experience Tour

\section{EXPERIENCE TOUR}

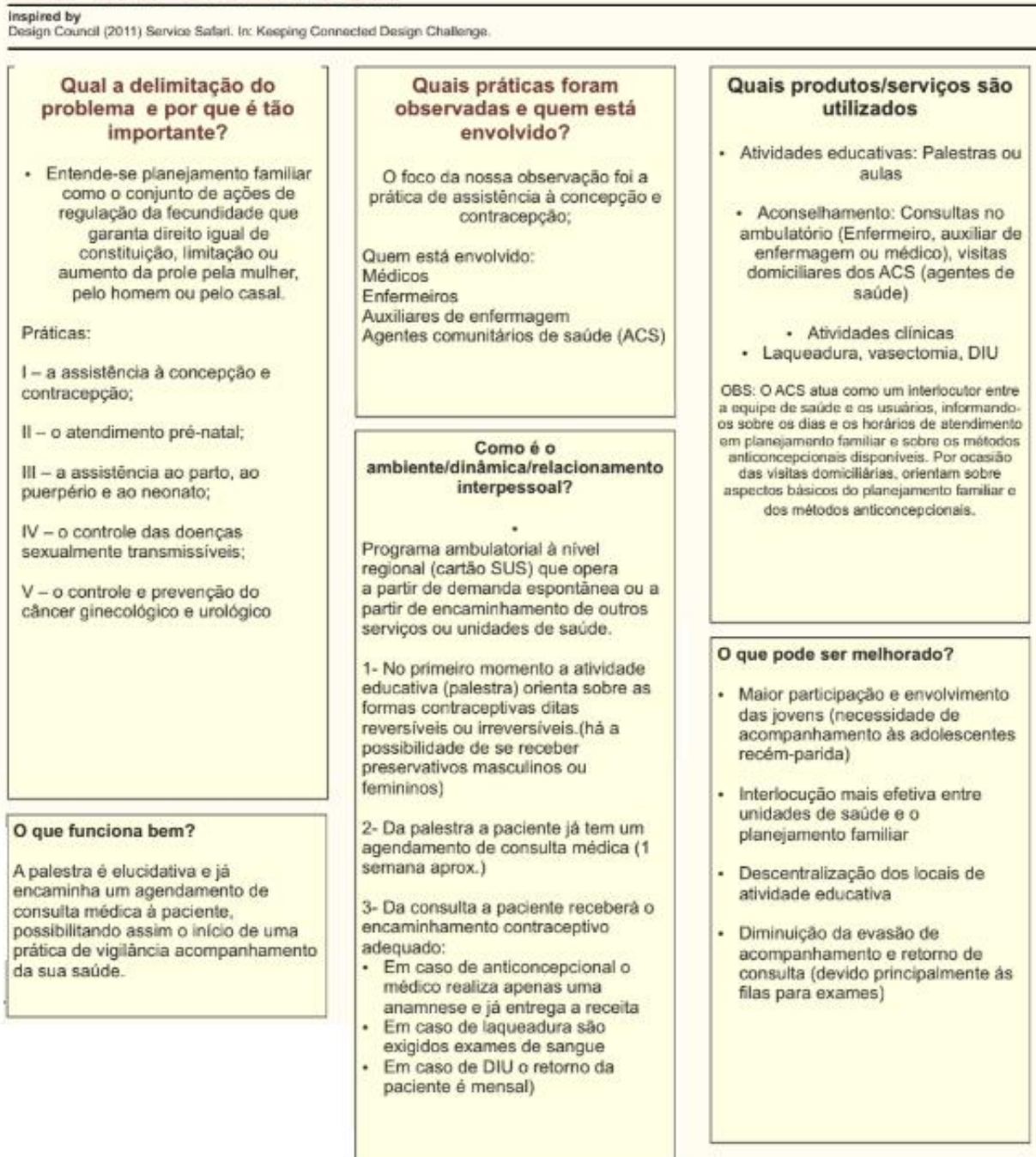

Fonte: Elaborado pelo autor, com base na pesquisa realizada 
A Ferramenta extraída do DIY, Development Impact \& You (2014), fornece uma estrutura para refletir e colecionar informações de suas experiências em primeira mão. Possui diretrizes para ajudá-lo a se concentrar nas experiências das pessoas que você está tentando entender e coletar o tipo de materiais que você precisará depois para começar a desenvolver ideia.

A partir dessa ferramenta foi possível visualizar a situação atual das reuniões de planejamento familiar na cidade do Recife e a necessidade de planejamento familiar em todo o Brasil.

\subsection{Análise SWOT}

A quarta etapa realizada foi a análise SWOT, a sigla significa Forças (Strengths), Fraquezas (Weaknesses), Oportunidades (Opportunities) e Ameaças (Threats). Esta análise leva a um entendimento mais rico de o que o projeto ou organização pode oferecer, as principais fraquezas que precisam ser trabalhadas para atingir o sucesso e onde buscar parceiros externos para assistência. Esta análise também foi extraída do DIY, Development Impact \& You (2014). A análise SWOT (Figura 3) fornece uma boa estrutura para revisão estratégicas e direções atuais, ou mesmo para testar uma ideia ao explorar soluções. É particularmente útil fazer uma análise SWOT antes do início de um projeto.

Figura 3: Análise SWOT

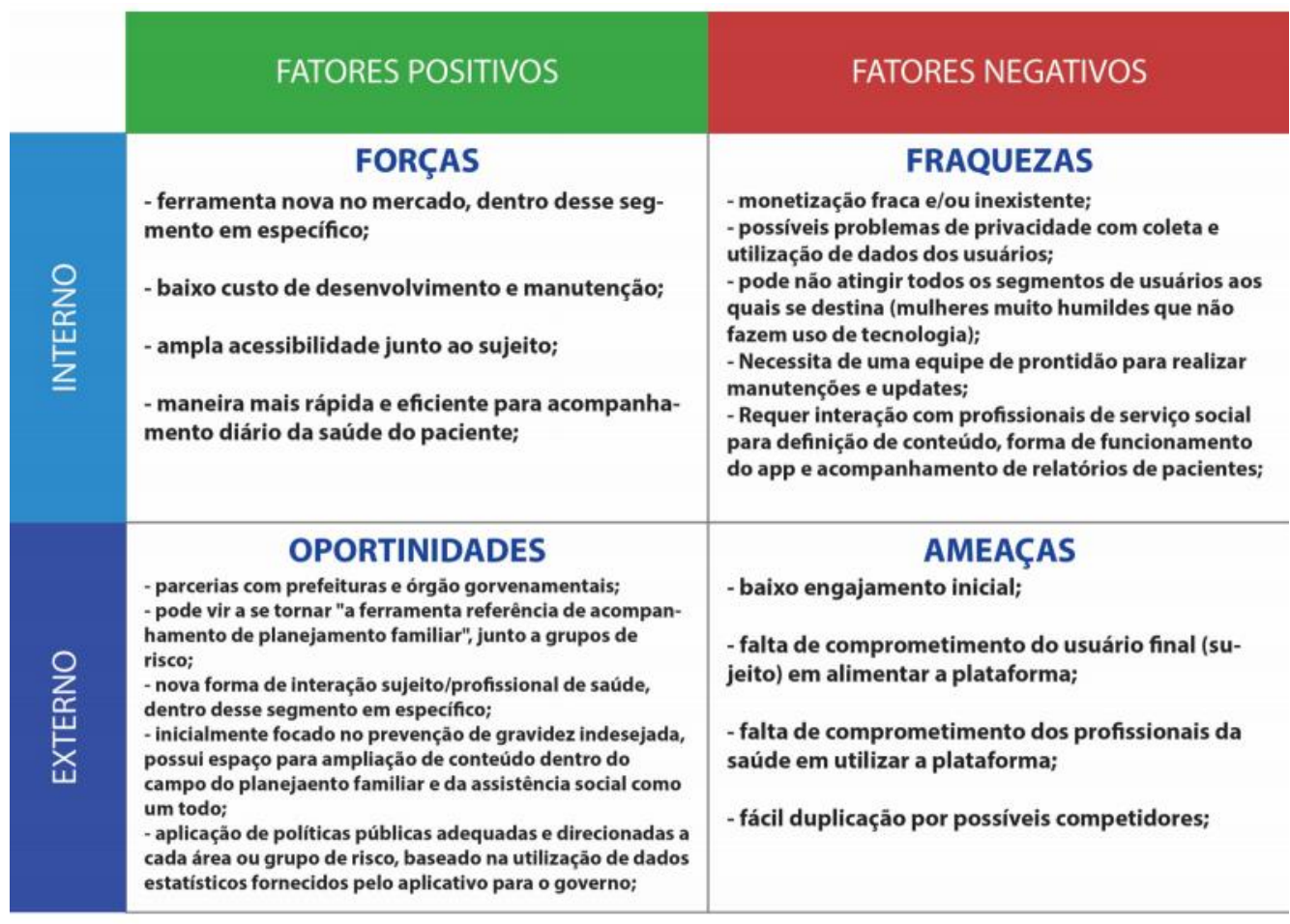

Fonte: Elaborado pelo autor, com base na pesquisa realizada

Com ela conseguimos visualizar as fraquezas e ameaças do projeto a fim de trabalhar para que essas sejam minimizadas. Para isso, fez-se necessário observar as reuniões e a experiência das pacientes. Desenvolve-se, então, um Storyworld (DIY, 2014) com a finalidade de guiar uma entrevista, dessa vez com as pacientes. 


\subsection{Storyworld}

A ferramenta Storyworld fornece uma estrutura capaz de destacar as informações mais relevantes de sua pesquisa. Ela ajuda você a fazer isso sem se surpreender com detalhes, mostrando como estruturar sua documentação para que as discussões que você tenha depois estejam em sintonia com os requisitos de aprendizagem.

Figura 4: Storyworld
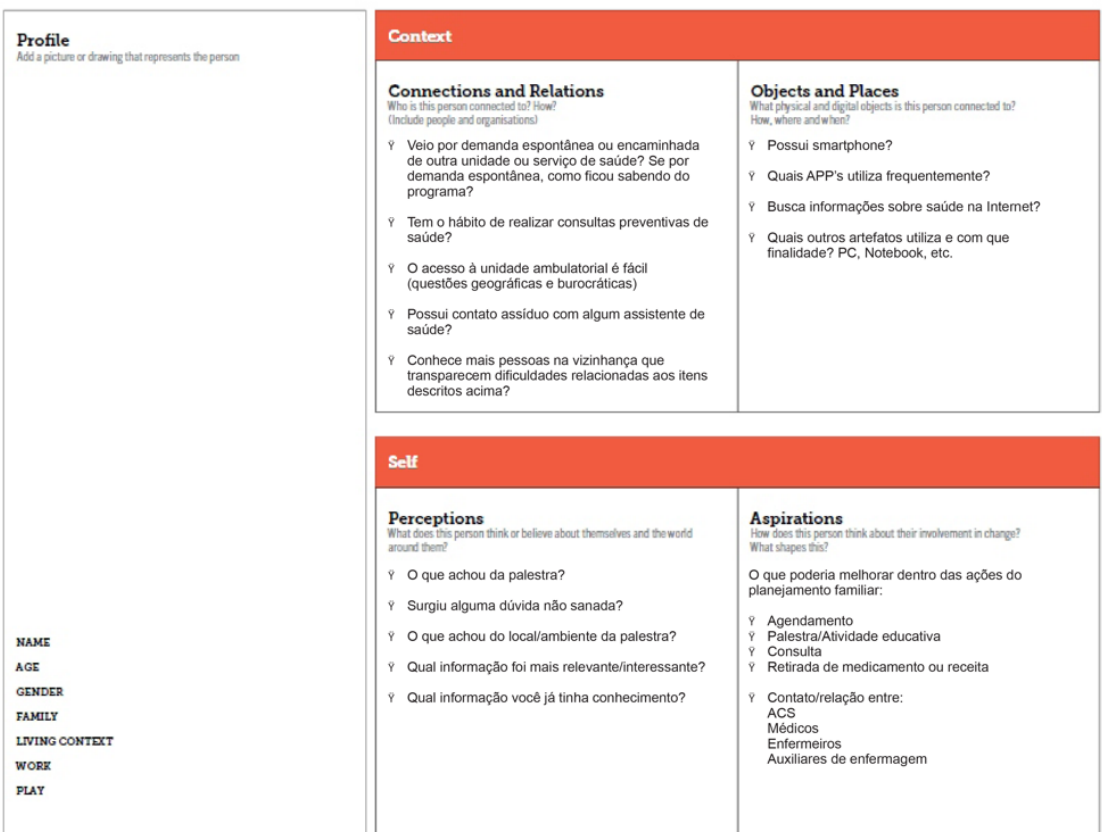

Memorable quotes
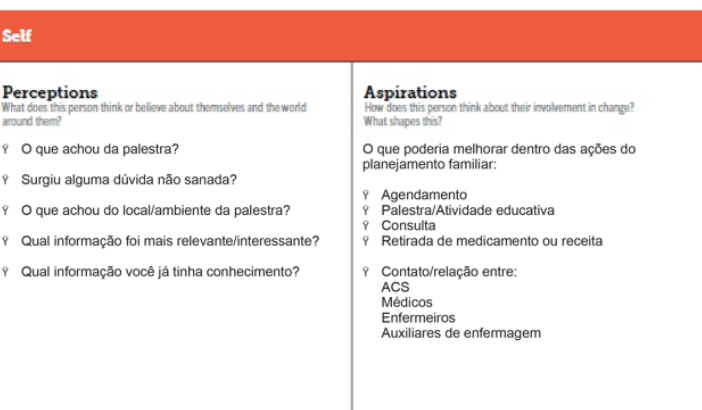

Fonte: Elaborado pelo autor, com base na pesquisa realizada

Figura 5: Storyworld - Context

\begin{tabular}{|c|c|}
\hline Context & \\
\hline 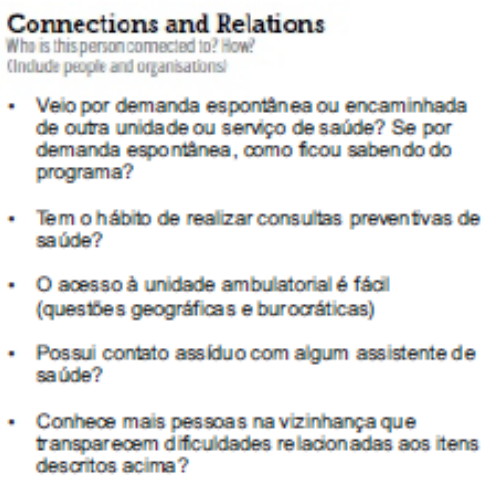 & 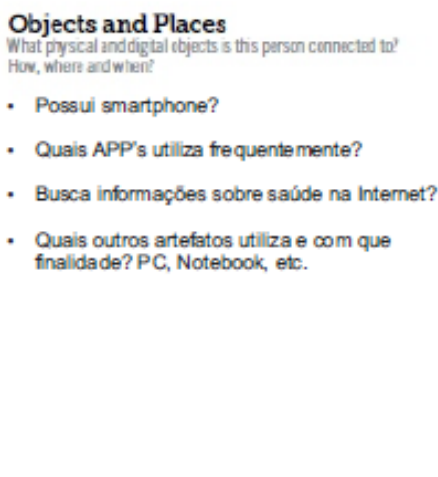 \\
\hline
\end{tabular}

Fonte: Elaborado pelo autor, com base na pesquisa realizada 
Figura 6: Storyworld - Self



Fonte: Elaborado pelo autor, com base na pesquisa realizada

\subsection{Observação direta intensiva participante}

A equipe foi à reunião com o Storyworld em mãos, mas não conseguiu aplicá-lo. Em vez disso, realizou uma observação direta intensiva participante artificial que consiste na participação real do pesquisador com a comunidade ou grupo, ou seja, ele se incorpora ao grupo e confunde-se com ele, ficando tão próximo quanto um membro do grupo que está estudando e participa das atividades normais deste (LAKATOS e MARCONI, 2007). O objetivo desta observação é conhecer o programa de planejamento familiar de perto e observar como vem sendo ministrada as palestras.

Figura 7: Experience Tour

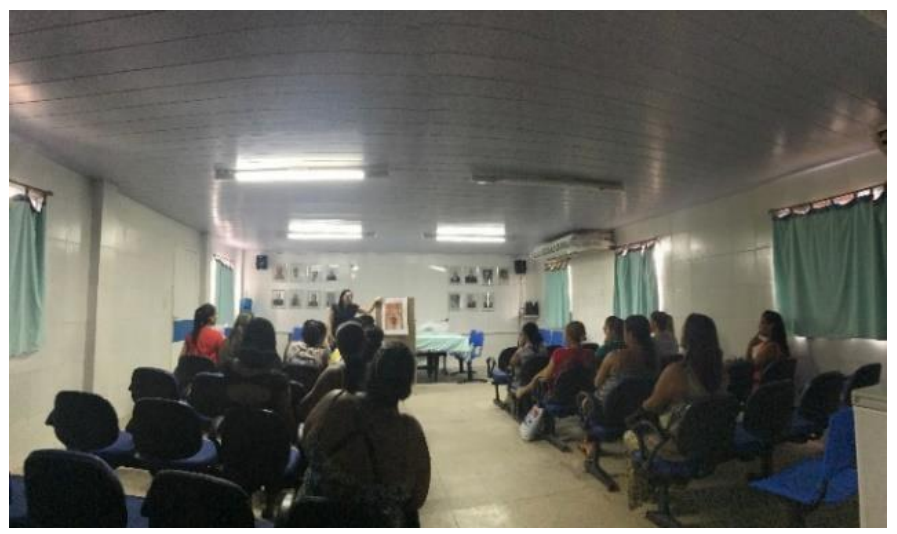

Fonte: Elaborado pelo autor, com base na pesquisa realizada

Na reunião haviam 19 mulheres. Não foi possível aplicar o Storyworld pois a palestra durou 1 hora e 38 minutos e muitas pacientes já haviam pedido para sair mais cedo pois tinham compromissos, de modo que foi necessário reformular como estas mulheres seriam entrevistadas. Portanto, um questionário objetivo foi desenvolvido a fim de realizar uma observação direta intensiva estruturada com todas as pacientes presentes. O Storyworld serviu de guia para a observação direta intensiva despadronizada sendo aplicado com pacientes que se voluntariaram a ter uma conversa mais longa após a palestra. 


\subsection{Observação direta intensiva estruturada}

Citando Lakatos e Marconi (2007), a observação direta intensiva estruturada é aquela que o entrevistador segue um roteiro previamente estabelecido. Ela se realiza de acordo com um formulário elaborado e é efetuada, de preferência, com pessoas selecionadas de acordo com um plano. Utiliza instrumentos para a coleta de dados ou fenômenos observados. O observador sabe o que procura e o que carece de importância.

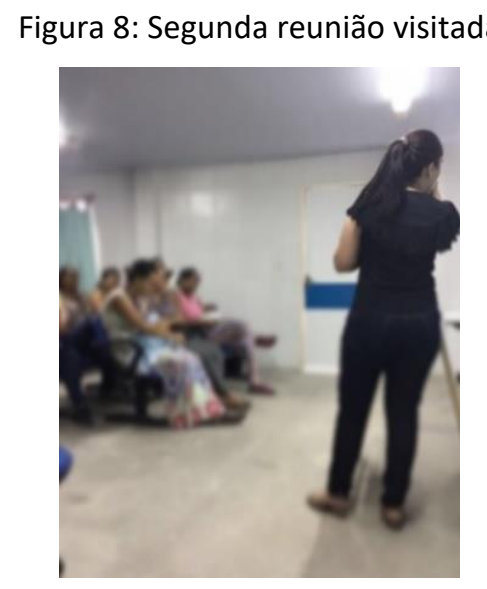

Fonte: Elaborado pelo autor, com base na pesquisa realizada

Na segunda reunião haviam 24 pacientes, as perguntas foram realizadas após o término da palestra, estando as respostas na tabela 1 abaixo. O Termo de Consentimento Livre e esclarecido (TCLE) foi lido em voz alta e entregue as pacientes que assinaram e permitiram a realização da pesquisa. O modelo do TCLE se encontra nos anexos do artigo.

O objetivo central desse questionário era analisar se essas mulheres utilizavam Smartfones, a fim de identificar se um aplicativo poderia ser o artefato digital a ser desenvolvido.

Tabela 1: Experience Tour

\begin{tabular}{|l|c|c|}
\hline \multicolumn{1}{|c|}{ Questionário aplicado com 24 mulheres } & Sim & Não \\
\hline Perguntas: & 24 & 0 \\
\hline Quem usa smartfones? & 24 & 0 \\
\hline Quem usa sites de busca para obter informações sobre temas gerais? & 5 & 19 \\
\hline Quem já pesquisou sobre os assuntos da palestra na internet? & 9 & 15 \\
\hline Quem baixaria um aplicativo do SUS para auxiliar nas orientações que tiveram na palestra? & 21 & 3 \\
\hline $\begin{array}{l}\text { Quem pode participar de uma entrevista hoje para auxiliar a entender as necessidades das } \\
\text { mulheres no programa de planejamento familiar? }\end{array}$ & 21 \\
\hline
\end{tabular}

Fonte: Elaborado pelo autor, com base na pesquisa realizada

\subsection{Observação direta intensiva despadronizada}

$\mathrm{Na}$ observação despadronizada focalizada o entrevistado tem liberdade para desenvolver cada situação em qualquer direção que considere adequada. Normalmente as perguntas são abertas e podem ser respondidas em uma conversação informal, seguindo um roteiro e tópicos. Serve para explorar mais amplamente uma questão. (LAKATOS E MARCONI, 2007). 
Com a entrevista guiada pelo Storyworld desenvolvido foi possível confirmar as seguintes afirmações:

1. É variada a forma como as mulheres tomaram conhecimento da palestra: ouviu de amigos e parentes ou recebeu indicação de outros postos de saúde;

2. Não possuem o hábito de realizar consultas preventivas;

3. A maioria não possui postos próximos e se queixaram da falta de informação;

4. São usuárias de aplicativos de redes sociais e entretenimento;

5. Utilizam a internet como fonte de pesquisa relacionada a saúde, mas nem sempre se sentem segura a respeito das fontes pesquisadas;

6. Utilizam tanto o computador como celular para acessar a internet;

7. Muitos temas novos foram aprendidos com a palestra;

8. Apenas tiveram contato, até então, com assistentes sociais;

Após a pesquisa bibliográfica e todas as entrevistas realizadas, foi possível detectar a necessidade de organização e disseminação das informações, de maneira que o grupo optou pela ideação de um aplicativo que tenha como objetivo auxiliar a interação entre os agentes de saúde do SUS e as pacientes do planejamento familiar.

Esse aplicativo exercerá as seguintes funções:

1. Localização de Postos de Saúde;

2. Informação sobre os métodos;

3. Acompanhamento de ciclo menstrual;

4. Agendamento de palestra;

5. Localização de farmácias ou clínicas de exames;

6. Rede de comunicação entre as pacientes agendadas para as palestras onde receberão informações prévias e poderão se comunicar posteriormente para troca de informações e dúvidas;

7. Via de comunicação com as assistentes sociais auxiliada por chatbot (programa de computador que tenta simular um ser humano na conversação com as pessoas).

Em seguida foi feito o Canvas, a fim de transformar essa ideia em um modelo de negócio.

\subsection{Business Model Canvas}

Business Model Canvas ou também conhecido como "Quadro de modelo de negócios" é uma ferramenta de gerenciamento estratégico, que permite desenvolver e esboçar modelos de negócio novos ou existentes. É um mapa visual pré-formatado contendo nove blocos do modelo de negócios. Foi inicialmente proposto por Alexander Osterwalder (2010) baseado no seu trabalho anterior sobre Business Model Ontology (2004).

A ferramenta é uma espécie de mapa dos pontos chaves de um plano de negócio, mas não exclui a construção dele, apenas é uma ferramenta menos formal que permite uma visão holística do negócio e que deve estar sendo sempre revisado cada quadrante ao longo do tempo, a fim de mensurar o resultado e propor alterações para melhoria.

Com a criação do modelo de negócio, concluímos a ideação da nossa ferramenta como um modelo de negócio sustentável e rentável, capaz de auxiliar uma necessidade social através de um artefato digital. 
Figura 9: Canvas Aplicativo

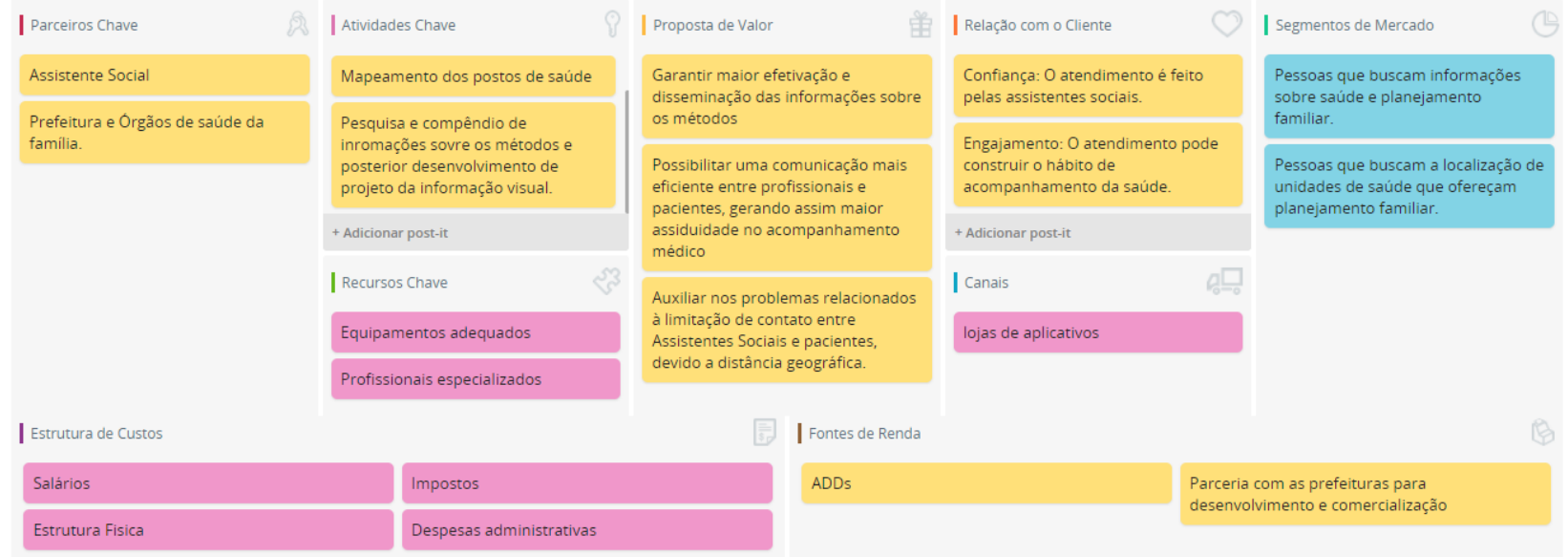

Fonte: Elaborado pelo autor, com base na pesquisa realizada

\section{CONCLUSÃO}

Todas as etapas metodológicas foram de suma importância para ideação da ferramenta e condução do projeto de maneira que fossem levadas em consideração as reais necessidades tanto das pacientes como das assistentes sociais responsáveis pelo programa. A figura10 representa o processo através de um infográfico. Algumas etapas tiveram de ser adaptadas para que pudessem ser aplicadas, como foi o caso do Storyworld, que só pode ser aplicado em um segundo momento, diferente do planejado. Através das entrevistas foi possível verificar que smartfones já fazem parte do universo dessas mulheres e que um aplicativo poderia ser uma ferramenta útil para o programa.

As amostras obtidas nas entrevistas não foram suficientes para colher dados quantitativos, assim, para melhor resultado se faz necessária a majoração dessas. $\mathrm{O}$ foco da pesquisa foram os dados qualitativos obtidos e que contribuíram bastante para o início do entendimento das necessidades das pacientes. Uma única maternidade foi entrevistada, o que não permite analisar o Programa de Planejamento Familiar como um todo, afinal o programa é nacional e a maternidade pesquisada pertence a prefeitura da cidade do Recife, no entanto possibilitou um estudo preliminar.

O aplicativo proposto é muito mais do que uma nova plataforma de comunicação do Sistema Único de Saúde (SUS), é a criação de rede entre essas pacientes, a conexão entre mulheres com características em comum que podem construir elos e dar suporte umas às outras além do ambiente digital, disseminando informações nos seus bairros e cidades. A ferramenta desenvolvida pode ser escalável e, também, pode ser reaplicável a outras áreas defasadas da saúde como prevenção aos diversos tipos de câncer, por exemplo.

Manzini (2013) resume Design para Inovação Social como sendo: "qualquer coisa que o design que pode fazer para começar, impulsionar, apoiar, fortalecer e replicar a inovação social".

Para continuar seguindo este conceito, as próximas etapas para concretização dessa ideação deverão manter este raciocínio: prototipar e avaliar o aplicativo com a participação conjunta dos agentes de saúde e pacientes. 
Figura 10: Infográfico do processo de criação do projeto

O PROCESSO DE CRIAÇÃO EM ARFETATOS DIGITAIS APLICADO AO DESIGN SOCIAL



Fonte: Elaborado pelo autor, com base na pesquisa realizada 


\section{REFERÊNCIAS}

BRASIL. Planejamento Familiar. Disponível em:< http://www.brasil.gov.br/saude/ 2011/09/planejamento-familiar>. Acesso em: 15 de novembro de 2017.

DINO, Lincoln Figueirôa Santos. Design de artefatos digitais baseados em padrões e plataformas. 2009. 96f. Tese (mestrado) - Universidade Federal de Pernambuco, Curso de Pós-Graduação em Design.

HAVES, Liliane Iten; FONSECA, Ken Flavio Ono. Design para inovação social: uma experiencia para inclusão do tema como atividade disciplinar. DAPesquisa, v. 11, p. 130-146, 2016.

HUGO, Mariana; MOURA, Heloisa. A contribuição do design para a inovação social sustentável. 2015. Disponível em: <https://www.uniritter.edu.br/files/sepesq/arquivos _trabalhos/3612/966/1112.pdf>. Acessado em: 20 de setembro de 2017.

KEANE, T.; et. al. DIY: Development Impact \& You. Practical tools to trigger \& support social innovation. 2014.

LAKATOS,E. M. \& MARCONI,M. A. Fundamentos de metodologia científica. São Paulo,Atlas, 1988. MANZINI, Ezio. Design para inovação social e sustentabilidade. Rio de Janeiro. e- papers, 2008.

MANZINI, Ezio. Making Things Happen: Social Innovation and Design. Design Issue, 30, 57-66. 2013.

MARTIN, Bella; HANINGTON, Bruce. Universal Methodsof Design:100 waystoresearchcomplexproblems, developinnovativeideas, and design effectivesolutions. RockportPublishers, 2012

MERONI, A. Creative communities. People inventing sustainable ways of living. Milano: Polidesign, 2007.

MINISTÉRIO DA SAÚDE. Pesquisa Nacional de Demografia e Saúde da Criança e da Mulher: PNDS 2006. Brasília, 2009. Disponível em:<http://bvsms.saude.gov.br/ bvs/publicacoes /pnds_crianca_mulher.pdf>. Acesso em: 15 de novembro de 2017.

MULGAN, Geoff, TUCKER, Simon, Ali, Rushanara and Sanders, Bem. Social Innovation: What it is, why it matters and how it can be accelerated. 2007. Skoll Centre for Social Entrepreneurship.

MURRAY, Robin; GRICE, Julie Caulier; MULGAN, Geoff. The open book of social innovation. Londres, 2010.

NAÇÕES UNIDAS NO BRASIL. OMS: 222 milhões de mulheres que não querem engravidar não têm acesso a contraceptivos. 2014. Disponível em:<https://nacoesunidas.org/oms-222-milhoesde-mulheres-que-nao-querem-engravidar-nao-tem-acesso-a-contraceptivos/>. Acesso em: 15 de novembro de 2017.

PHILLS, James A; DEIGLMEIER, Kriss; MILLER, Dale T. Rediscovering Social Innovation-Standford Social Innovation Review -Fall 2008.

ROBERT, Richard. Is social innovation the future of the economy? 2011. Disponível em:<http://parisinnovationreview.com/articles-en/is-social-innovation-the-future-of-theeconomy>. Acesso em: 15 de novembro de 2017. 
YAMAOKA, Eloi J.; GAUTHIER, Fernando O. Objetos digitais: em busca da precisão conceitual. Informação \& Informação, v. 18, n. 2, p. 77-97, 2013.

\section{ANEXOS}

\section{TERMO DE CONSENTIMENTO LIVRE E ESCLARECIDO}

Declaro, por meio deste termo, que concordei em ser entrevistada e/ou participar na pesquisa de campo referente ao projeto intitulado: $O$ processo de criação em artefatos digitais aplicado ao design social: Planejamento familiar, desenvolvido pelos mestrandos, alunos da Pós-graduação em Design da UFPE: Maria Paula de Araujo Caio, Rodrigo Mazulo, Manoel Deisson Xenofonte Araújo. Fui informado(a), ainda, de que a pesquisa é orientada por Profs. Leonardo Castillo e Ney Dantas, a quem poderei contatar / consultar a qualquer momento que julgar necessário através do telefone no 2126.8907 .

Afirmo que aceitei participar por minha própria vontade, sem receber qualquer incentivo financeiro ou ter qualquer ônus e com a finalidade exclusiva de colaborar para o sucesso da pesquisa. Fui informado(a) dos objetivos estritamente acadêmicos do estudo, que, em linhas gerais é fornecer informações para elaboração de um artefato digital que auxilie o programa de Planejamento Familiar do SUS.

Fui também esclarecida de que os usos das informações por mim oferecidas estão submetidos às normas éticas destinadas à pesquisa envolvendo seres humanos, da Comissão Nacional de Ética em Pesquisa (CONEP) do Conselho Nacional de Saúde, do Ministério da Saúde.

Minha colaboração se fará de forma anônima, por meio de entrevista a ser gravada a partir da assinatura desta autorização. $O$ acesso e a análise dos dados coletados se farão apenas pelos Pesquisadores e/ou seus orientadores.

Fui ainda informada de que posso me retirar dessa pesquisa a qualquer momento, sem prejuízo para meu acompanhamento ou sofrer quaisquer sanções ou constrangimentos.

Atesto recebimento de uma cópia assinada deste Termo de Consentimento Livre e Esclarecido, conforme recomendações da Comissão Nacional de Ética em Pesquisa (CONEP).

Recife, de de

Assinatura do(a) participante:

Assinatura do(a) pesquisador(a):

Assinatura do(a) testemunha(a): 